\title{
Reduplicative paramnesia: possible anatomical and neuropsychological mechanisms
}

\author{
NARINDER KAPUR, ALAN TURNER, CHRISTOPHER KING \\ From the Wessex Neurological Centre, Southampton, UK
}

SUMMARY A patient is reported who presented with reduplicative paramnesia following a vascular lesion in the right frontal region. Neuropsychological examination revealed significant memory impairment, perseveration on a problem solving task and marked left-sided inattention. Recovery from the paramnesic episode was accompanied by selective resolution of the original cognitive deficits. It is suggested that focal right frontal pathology may represent a sufficient condition for the occurrence of reduplicative paramnesia, and that the underlying mechanisms may be dependent on a particular combination and severity of memory, visuospatial and conceptual deficits.

Confabulation is perhaps the most dramatic of the various types of memory disturbance seen after frontal lobe lesions, ${ }^{1-4}$ and may range from spontaneous, implausible invention which bears little relationship to past events, and includes fabrication of future intentions and misuse of environmental cues, to more subtle distortions of recall of past events, perhaps in the wrong temporal or spatial context. One of the more florid types of confabulation is reduplicative paramnesia, where the patient may claim that there are two forms of the same place or may confuse his present place of residence for another place with which it shares some features. This type of confabulation has been reported by a number of researchers, ${ }^{5-7}$ but there remains some uncertainty as to the minimal lesion necessary for reduplicative paramnesia to occur, and as to the mechanisms which may underlie this memory disorder.

\section{Case history}

RS, a 71 year old right-handed man, who had previously worked as an aircraft inspection officer, left his home in Portsmouth on the morning of 1 April 1987 to go to a friend's house 6-7 miles away. Having spent the morning there, he left this house at approximately $3.30 \mathrm{pm}$ in good health, and intended to catch a bus back to his home. He did not, however, reach home at the intended time and was "missing" for 5 hours. At $8.45 \mathrm{pm}$, he arrived at his house in

Address for reprint requests: Dr N Kapur, Wessex Neurological Centre, Tremona Road, Southampton SO9 4XY, UK.

Received 18 August 1987 and in revised form 9 November 1987. Accepted 17 November 1987 a taxi. RS recognised his daughter when she came out to the taxi, but asked her what she was doing at this place. He indicated that he was sure this house was not his real home. When he came into the house, he recognised his wife and his other daughter and at no stage showed any symptoms suggestive of a Capgras syndrome (that is, misrecognition of a familiar figure with the belief that one of them is a "double" who resembles the real person). However, he continued to insist that the house was not his "real" house, and remarked on how striking it was that the owners of this house had the same ornaments as he had in "his" house and on what a coincidence it was that there were similar items beside the bed as there were in "his" house. RS continued to have this paramnesia over the next $\mathbf{4 8}$ hours till his admission to hospital, though there were periods during this time when he would temporarily appear to accept the reassurances of his family that he was in fact in his own home. On 4 April, he was admitted to St Mary's Hospital, Portsmouth, and on 13 April he was transferred to the Wessex Neurological Centre in Southampton where neurological examination revealed no focal physical signs. Perimetric examination of visual fields did not elicit any visual field loss. A CT scan (fig) showed an area of haemorrhage in the right frontal area, with some surrounding cerebral oedema. At interview, RS continued to insist that there were two "Riverside Avenues" (the real name of the street has been substituted to ensure the patient's anonymity) and that he was sure he had gone from the first house to the "real one" in the few days after the episode. RS was able to indicate the town in which he was at the time of his examination (Southampton), but thought he had been there for 3 weeks (he was interviewed the day after his admission). However, shortly afterwards he indicated that he arrived at Southampton General Hospital the day before, having come from another nearby hospital where he had been for a few hours. He had difficulty in naming this other hospital, and mentioned the words "Wessex General 


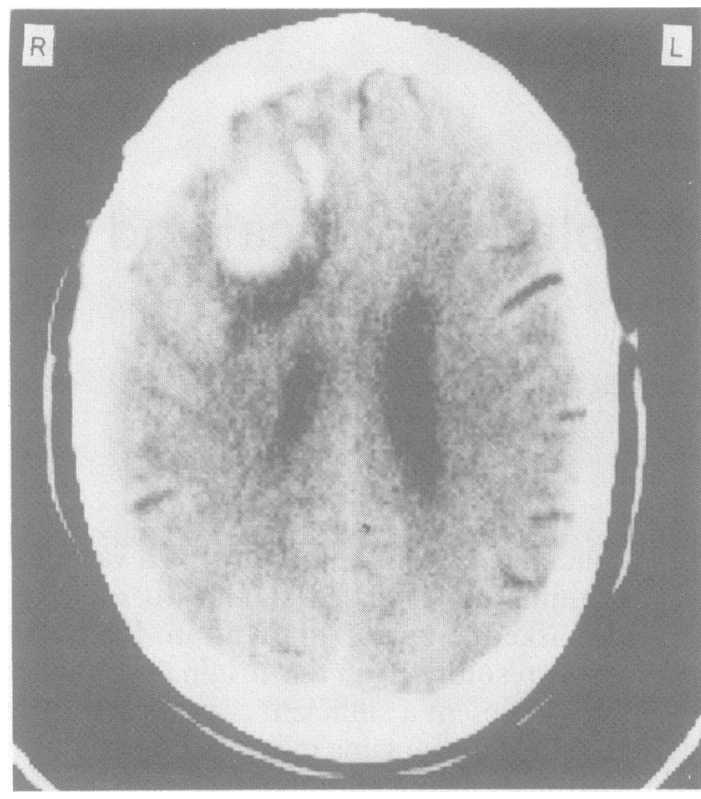

Fig CT scan showing area of haemorrhage in right frontal region.

Hospital" and "Hollywood Hospital" (no hospital of this name exists in this or in other areas). When offered the name "Wessex Neurological Centre" he accepted this as being the hospital where he had been the previous day for a few hours. He thought that this centre was 4-5 miles away from the hospital where he was being examined (the Wessex Neurological Centre is in fact an integral part of Southampton General Hospital). RS was discharged from the Wessex Neurological Centre several days later.

On 28 April, RS was interviewed at home. he was oriented for time and place, and remembered having seen the clinician (NK) before. Asked how many Riverside Avenues he thought there were, he indicated that he still thought there were two, but that he could not prove this. He incorrectly indicated on a map of Portsmouth the location of his own home, that is, where the interview was taking place. RS was asked how long he had been home from hospital, and he correctly gave the duration as being 7 days. Asked where he had previously been, he incorrectly said "St James' Hospital" (this is a psychiatric hospital in Portsmouth). Asked where he had been prior to this, he said "St Mary's Hospital, Southampton" (this hospital does not exist). Asked where he had been prior to this, he said "quite a few hospitals" and proceeded to name St Mary's Hospital, Hayling Island (this hospital does not exist), Queen Alexandra Hospital (this hospital does exist), and St Mary's Hospital, Fareham (this latter hospital also does not exist).

RS was re-examined 3 months later at the Wessex Neurological Centre in Southampton General Hospital. On this occasion, he did not display any symptoms of reduplicative paramnesia, either spontaneously or to direct prompting. He was fully oriented for place, and denied any confusion in respect of his place of abode, indicating that his "mind was clear of this now". On a map of Portsmouth, he correctly indicated the area in which he lived. He did not report any everyday memory difficulties, though his family thought that he was occasionally a little more forgetful than before his illness.

\section{Neuropsychological investigations}

At the time of his admission to the Wessex Neurological Centre, RS was administered five Verbal and four Performance subtests from the Wechsler Adult Intelligence Scale-Revised. ${ }^{8} \mathrm{He}$ obtained a pro-rated Verbal IQ of 78, a Performance IQ of 78 and a Full Scale IQ of 79. His agescaled scores on individual subtests were: Digit Span-6, Vocabulary-8, Arithmetic-5, Comprehension-8, Similarities-4, Picture Completion-12, Picture Arrangement-0, Block Design-4, Digit Symbol-8. RS performed particularly poorly both on tests of verbal reasoning and computation (Similarities and Arithmetic) and on tests of non-verbal reasoning and perceptual-motor ability (Picture Arrangement and Block Design). On the Picture Completion test, RS showed evidence of left-sided visual inattention on item 4; instead of indicating that the set of eight diamonds needed an extra diamond to make the picture complete, he responded that the picture needed five more diamonds to make it complete. On a word-list learning task, ${ }^{9}$ he showed a mild-moderate impairment. On a verbal recognition memory test, ${ }^{10}$ interpretation of his performance was complicated by his left-sided inattention; he consistently chose items on the right column of the twochoice arrays, even when the two choices were read aloud to him. On tests of nonverbal memory, RS showed more marked impairment. On a faces recognition memory test, ${ }^{10}$ he showed a mild-moderate degree of impairment, scoring at the 25th percentile for the over 55 years age-group. On a visual design learning test, ${ }^{9}$ RS showed a moderate impairment, performing between the 10th and 25th percentile on various measures of this test. RS's copy of the Rey-Osterreith complex figure showed a significant degree of impairment ( 21.5 out of a maximum of 36 points), with evidence of left-sided inattention. On a verbal fluency test, ${ }^{11}$ RS scored at the 8th percentile, and he was also impaired on the Modified Card Sorting Test, ${ }^{12}$ producing $68 \%$ of perseverative responses. In summary, there appeared therefore to be three main sets of cognitive deficits on neuropsychological examination: non-verbal memory deficits, leftsided inattention and impaired performance on tests of problem solving/sustained attention.

RS was re-assessed 3 months later. On this occasion, he had a pro-rated Verbal IQ of 88, Performance IQ of 101 and Full Scale IQ of 91. The main subtests which showed an increase from the assessment in April were Similarities (agescaled score of 9 (4 in April), Picture Arrangement-10 (0)), and Block Design-10 (4). His copy of the Rey-Osterreith figure also showed significant improvement, and no longer displayed left-sided neglect, though it was slightly impaired (30.5/36 points). His memory performance showed selective improvement. On recognition memory testing, ${ }^{10}$ he obtained an age-scaled score of 9 for verbal items (within normal limits), and did not show the marked left-sided inattention which was a feature of his earlier performance on this test; his memory for faces was still impaired, with an age-scaled score of 5 . On the verbal list learning task ${ }^{9}$ given 
earlier, his performance was essentially unchanged, and he still showed the mild-moderate impairment which was evident on the original testing. However, on the design learning test he showed a significant improvement, with his scores on all parts of this task falling at or above the 50th percentile. On the Modified Card Sorting Test given at the initial assessment, RS showed little change; he was only able to achieve two categories, and $73 \%$ of his errors were perseverative errors. His verbal fluency performance, for the letters $c, f$ and 1 , showed a slight improvement, and was now at the 22nd percentile. In summary, RS showed improved performance on most visuospatial tasks and in certain aspects of memory functioning, but he continued to show perseveration on a problem solving task.

\section{Discussion}

Our patient displayed several instances of reduplicative paramnesia after incurring a right frontal vascular lesion. Neuropsychological testing indicated three sets of cognitive impairment: memory disturbance, visuospatial deficits which included a significant degree of left-sided inattention, and impaired reasoning ability. Three months later, our patient did not have any symptoms of reduplicative paramnesia; at the neuropsychological level, he showed some improvement in memory, visuospatial functioning, and verbal reasoning, but he continued to show deficits, particularly on some aspects of nonverbal memory and problem solving ability.

Our case may help to shed some light on the anatomical basis of reduplicative paramnesia. Some authors have implicated bilateral cerebral pathology (for example ref 13 ), and Benson et al, ${ }^{7}$ specifically proposed that right hemisphere and bilateral frontal pathology were necessary for the condition to occur. Other authors ${ }^{1415}$ have pointed to more limited, right hemisphere pathology as being critical in such patients. Vighetto et al ${ }^{16}$ and Fisher ${ }^{17}$ pointed out that disorientation for place can occur after right posterior cerebral lesions, and one of Fisher's patients, who incurred a right parieto-occipital infarction, did offer some symptoms of reduplicative paramnesia, though the errors offered by the patients in these two studies did not appear to be as florid as those displayed by our patient. We would propose that although disorientation for place may occur after right posterior cerebral pathology, acute right frontal pathology (in conjunction with the cognitive deficits described below), is both a necessary and sufficient condition for florid symptoms of reduplicative paramnesia to be present.

At the neuropsychological level, our findings are in general accord with the hypothesis offered by Patterson and Mack, ${ }^{6}$ namely that three separate sets of cognitive deficits are necessary for reduplicative paramnesia to occur: impairment of memory, some forms of attentional/spatial deficit and an impairment in conceptual integration. The fact that RS continued to show deficits on certain tasks, for example faces memory, card sorting performance, suggests that these deficits in themselves were not critical to the reduplicative paramnesia which he initially displayed.

The relative absence of change on tests of "frontal lobe functioning" over the recovery period shown by our patient contrasts with the improvement on such tests shown by the patient with frontal lobe vascular pathology studied by Kapur and Coughlan. ${ }^{2}$ The form of confabulation displayed by the latter patient was somewhat less specific than that shown by the patient in the present investigation, and it may be the case that different forms of confabulation are subserved by different neural mechanisms.

\section{References}

1 Stuss DT, Alexander MP, Lieberman A, Levine H. An extraordinary form of confabulation. Neurology 1978;28:1166-72.

2 Kapur N, Coughlan AK. Confabulation and frontal lobe dysfunction. J Neurol Neurosurg Psychiatry 1980;43:461-63.

3 Damasio AR, Graff-Radford NR, Eslinger PJ, Damasio H, Kassell N. Amnesia following basal forebrain lesions. Arch Neurol 1985;42:263-71.

4 Kapur N. Memory Disorders in Clinical Practice. London: Butterworths, 1988, (in press).

5 Paterson A, Zangwill OL. Recovery of spatial disorientation in the post-traumatic confusional state. Brain 1944;67:54-68.

6 Patterson MB, Mack JL. Neuropsychological analysis of a case of reduplicative paramnesia. J Clin Exp Neuropsychol 1985;7:111-21.

7 Benson DF, Gardner H, Meadows JC. Reduplicative paramnesia. Neurology 1976;26:147-51.

8 Wechsler D. Wechsler Adult Intelligence Scale-Revised. New York: Psychological Corporation, 1981.

9 Coughlan AK, Hollows SE. The Adult Memory and Information Processing Battery. St James's University Hospital, Leeds, AK Coughlan, 1985.

10 Warrington EK. Recognition Memory Test. Windsor: NFER-Nelson, 1984.

11 Benton AL, Hamsher K. Multilingual Aphasia Examination. Iowa City: University of Iowa, 1978.

12 Nelson HE. A modified card sorting test sensitive to frontal lobe defects. Cortex 1976;12:313-24.

13 Weinstein EA, Kahn RL, Sugerman LA. Phenomenon of reduplication. Arch Neurol Psychiatry 1952;67:808-14.

14 Ruff RL, Volpe BT. Environmental reduplication associated with right frontal and right parietal lobe injury. $J$ Neurol Neurosurg Psychiatry 1981;44:382-6.

15 Staton RD, Brumback RA, Wilson H. Reduplicative paramnesia: a disconnection syndrome of memory. Cortex 1982;18:23-36.

16 Vighetto A, Aimard G, Confavreux C, Devic M. Une observation anatomoclinique de fabulation (ou delire) topografique. Cortex 1980;16:501-7.

17 Fisher CM. Disorientation for place. Arch Neurol 1982;39:33-6. 